\title{
Temporal changes and determinants of childhood nutritional status in Kenya and Zambia
}

Daniel Hoffman ${ }^{1,2^{*}}$ (D) Thomas Cacciola ${ }^{1,2}$, Pamela Barrios ${ }^{1,2}$ and James Simon ${ }^{2,3}$

\begin{abstract}
Background: The prevalence of undernutrition is decreasing in many parts of the developing world, but challenges remain in many countries. The objective of this study was to determine factors influencing childhood nutrition status in Kenya and Zambia. The objective of this study is to determine factors associated with temporal changes in childhood nutritional status in two countries in sub-Saharan Africa.

Methods: Data from national demographic and health surveys from the World Bank for Kenya (1998-2009) and Zambia (1996-2014) were used to select the youngest child of each household with complete data for all variables studied. Multiple linear regression analyses were used for data from 2902 and 11,335 children from Kenya and Zambia, respectively, in each year to determine the relationship between social and economic factors and measures of nutritional status, including wasting, stunting, and overweight.

Results: There was a decreased prevalence of stunting (35\% in Kenya and $40 \%$ in Zambia), while the prevalence of wasting was unchanged (6-8\% in both countries). From 1998 to 2009, there was a protective effect against stunting for wealthier families and households with electricity, for both countries. Finally, better educated mothers were less likely to have stunted children and girls were less likely to be stunted than boys.

Conclusions: Based on the data analyzed, there was a higher risk of stunting in both Kenya and Zambia, for those with lower literacy, less education, no electricity, living in rural areas, no formal toilet, no car ownership, and those with an overall lower wealth index. Improving the education of mothers was also a significant determinant in improving the nutritional status of children in Kenya and Zambia. More broad-based efforts to reduce the prevalence of undernutrition need to focus on reducing the prevalence of undernutrition without promoting excess weight gain. Future economic advances need to consider integrated approaches to improving economic standings of households without increasing the risk for overnutrition.
\end{abstract}

Keywords: Stunting, Wasting, Nutritional status, Children, Kenya, Zambia, Dietary diversity

\footnotetext{
* Correspondence: dhoffman@aesop.rutgers.edu

${ }^{1}$ Department of Nutritional Sciences, Rutgers University, New Brunswick, NJ,

USA

${ }^{2}$ New Jersey Institute for Food, Nutrition, and Health, Center for Childhood

Nutrition Education and Research, Program in International Nutrition, Rutgers

University, 61 Dudley Road, New Brunswick, NJ 08901, USA

Full list of author information is available at the end of the article
} 


\section{Background}

The prevalence of obesity is a major public health problem in most developed and many transitional countries and has also contributed to the "double burden of disease", the coexistence of both obesity and underweight [1-5]. The double burden is not necessarily a reflection of competing problems [6] and the fact that excess weight gain is now co-existent with low-weight underscores the need to better understand how chronic nutrition problems change over time and within specific socio-geographic regions. To that end, it is of interest to better understand what factors influence temporal changes in nutritional status, especially in less developed regions that have yet to experience the double burden of disease, such as Sub-Saharan Africa. Therefore, the focus of this paper is to describe the current state of childhood nutrition in Kenya and Zambia and determine factors associated with temporal changes in childhood nutritional status.

In terms of childhood nutrition, a high prevalence of chronic malnutrition has been reported in both urban and rural settings throughout Africa [7-13]. For example, a high percentage of children are stunted, underweight, or wasted, in Nairobi, Kenya, but most especially within informal urban settlements $[11,14]$. For example, in the Dagoretti Division of Nairobi, $24.5 \%$ of children aged 4-11 were stunted, $14.9 \%$ were underweight, and 9.7\% were wasted [14]. At the same time, more boys than girls are undernourished; however, there are some conflicting results with different trends emerging between separate regions [11, 14-16]. Specifically, a higher percentage of boys were stunted compared to girls [14]. In Kibera, an informal settlement in Nairobi, one survey of 1310 children aged $6-59$ months found that $47.0 \%$ of children were stunted (severe stunting in $23.4 \%$ of the children), $11.8 \%$ were underweight (severe underweight in $3.1 \%$ ), and $2.6 \%$ were wasted (severe wasting in $0.6 \%$ ) [11]. Moreover, girls were more likely than boys to be wasted at 3 years of age compared to boys. Such gender differences in these data may arise from a number of cultural or economic factors that favor one gender over the other. These studies highlight the fact that poor nutrition is most prevalent in impoverished and marginalized areas, but the cross-sectional nature of the research does not allow for broader conclusions regarding how social determinants of nutritional status may change with time.

With regards to undernutrition, the prevalence of stunting or wasting varies across Sub-Saharan Africa and even within rural regions of Kenya. One recent study reported that fetal growth restriction and poor sanitation are the primary predictors of stunting in many parts of the world, but most particular for Sub-Saharan Africa [7]. Within country data are more illustrative, such that in the rural Bondo district of Kenya, 30\% of children under the age of 5 were stunted ( $12 \%$ severely stunted), $4 \%$ were wasted
(1\% severely wasted), and $20 \%$ were underweight (5\% severely underweight) with height and weight deficits most prevalent for children aged 18-23 months [10]. Meanwhile, in the Suba district, children between the ages of 11 and 16 years had the highest percentages of undernourished subjects and the most severe undernutrition with boys more likely to be stunted and underweight compared to girls. One study of malnutrition rural Kenya found that among children under the age of 60 months, there was a higher prevalence of malnutrition among girls compared to boys. In addition, girls also tended to have lower overall energy intake compared to boys. In particular, of the 629 subjects surveyed in the Mwingi and Makueni districts, stunting, underweight, and wasting were all more prevalent among girls [16]. Thus, gender differences may confound other determinants of nutritional status, emphasizing the need for more comprehensive research on factors that influence childhood nutritional status.

In Zambia, one study of children from the Samfya district found that food intake of infants and toddlers was insufficient such that total energy, calcium, iron, and vitamin A were below recommended daily intake for both infants and toddlers, while infants were also below the recommended intake for protein [9]. Moreover, weaning foods consumed by toddlers were found to be inadequate as well, increasing the risk for continued nutritional deficits during childhood [9]. A study from the Chroma district reported poor nutritional status in a sample of 388 children aged 24-59 months and among children aged 12-23 months, only $40 \%$ were adequately nourished [13]. Finally, one study in Zambia focused on adults in the Katete district and reported that lower selfperceived socioeconomic status was related to a lower adult BMI in the sample of 254 men and women [17].

In summary, it is clear that undernutrition continues to be a serious problem that persists in these two countries of Eastern Africa [18-20]. However, while these studies have consistently reported a high prevalence of childhood undernutrition, they often do not extend the research to determine how nutritional status is affected by other factors, such as urbanization, education, and maternal autonomy. Therefore, additional research is need to better understand how various social and economic conditions can be modified to promote better nutritional status of children and adults in both countries. The objective of this paper is to determine socioeconomic factors that influence childhood nutritional status in a temporal setting using nationally representative data from Kenya and Zambia.

\section{Methods}

Using data from the Health Nutrition and Population Statistics of national demographic and health surveys (DHS) at the World Bank [20], the prevalence of stunting and 
wasting was calculated using available years for both Kenya and Zambia. The sampling framework for DHS is fully covered in the manual for DHS data collection [21]. Briefly, the ministry responsible for DHS can submit data collected only if the survey follows key principles explained in detail in the DHS manual. Such principles include the use of an existing sampling frame that provides full coverage of the target population (such as households with children) and is conducted using a random design with a sample size consistent with the manual. In addition, households sampled must conform to the selection criteria and strict confidentiality is maintained. Datasets were extracted from the World Bank website for each country and year studied. Statistical analyses were conducted on the datasets after the deletion of missing values, implausible values, and only respondents with all available data for each variable studied were included. After data cleaning, the final dataset studied for each country included more than 2500 children (ages birth to 4 years) for each year in both Kenya and Zambia. For each outcome of interest, social and economic factors that may influence each was analyzed using stepwise linear regression to best determine how such factors are modified by year of each survey. Using this method allowed for us to determine how specific factors that are associated with nutritional status vary as time progresses, especially in light of the fact that each country has experienced consistent economic growth of $5 \%$ of greater since the mid-1990s 20, 21. All data were analyzed using SPSS version 22 (IBM SPSS Statistics, NY, USA) and statistical significance was set a $p<0.05$.

\section{Nutritional status}

The prevalence of stunting and wasting in Kenya and Zambia was calculated according to the WHO guidelines [22] in which stunting was defined as a height-forage $\mathrm{Z}$-score $(\mathrm{HAZ})<-2.00$ and wasting was defined as a weight-for-height $\mathrm{Z}$-score $(\mathrm{WHZ})<-2.00$. Overweight was defined as $\mathrm{WHZ}<2.00$ and $\mathrm{BMI}$ percentile for age above $85 \%$. According to the conceptual framework of poverty proposed by UNICEF [23], nutritional status is the outcome of a complex hierarchy of factors that begins with direct exposure to quality diet and health care and extends to more indirect interactions with social and economic infrastructure that contribute to a myriad of socio-environmental factors that ultimately contribute to a child's nutritional status.

Multivariate logistic regression analyses were used to determine how social and economic factors contribute to risk of stunting and wasting, as well as potential changes across time. Specifically, the main outcomes of stunting and wasting were entered as the dependent variables in two models for each country. Known risk factors for these conditions were entered as independent variables, including wealth index, number of household members, rural or urban setting, type of toilet, maternal age, maternal educational status, and age and sex of the child. Backward stepwise analyses were conducted and only the statistically significant independent variables were included in each year analyzed for each country. This was the preferred method to determine if specific variables differed in terms of influencing the nutritional status of the child over the time period studied.

\section{Results}

A summary of the temporal changes in childhood nutritional status is presented in Table 1. The prevalence of stunting in Kenya averaged 35\% for the years analyzed while the prevalence in Zambia decreased from $50 \%$ in 1996 to $40 \%$ in 2014 . Wasting remained a less prevalent condition with an average of $7 \%$ of Kenyan and $6 \%$ of Zambian children suffering from wasting. At the same time, approximately $6 \%$ of Kenyan and Zambian children are classified as overweight (Table 2 and Table 3).

Results of the multivariate logistic regression analyses are summarized in Tables 4 and 5 for stunting and wasting, respectively. With regards to socio-economic factors in Kenya, the higher the wealth index of a family, the lower the risk of having a stunted child for all years analyzed. For 1998 and 2008 only, those households that reported having electricity were less likely to have a stunted child compared to those without electricity. There were no significant results for the number of family members, household setting, or type of toilet for any of the years analyzed.

Regarding maternal-child characteristics, more educated mothers were $50-80 \%$ less likely to have a stunted child compared to mothers with no or primary education only. However, the degree to which education reduced the odds of having a stunted child was not as great in 2009 compared to 1998. Older children were more likely to be stunted than younger children in 1998 and 2008, but not in other years. Finally, for all 3 years analyzed, girls were less likely to be stunted compared to boys.

The relationship between the socio-economic factors and stunting in Zambia were similar to what was found in Kenya. However, in Zambia, a large family decreased

Table 1 Nutritional status (\%) of children in Kenya and Zambia in selected years of available data

\begin{tabular}{|c|c|c|c|c|c|c|c|}
\hline \multirow[b]{2}{*}{ Year } & \multicolumn{3}{|c|}{ Kenya } & \multicolumn{4}{|c|}{ Zambia } \\
\hline & 1998 & 2003 & 2009 & 1996 & 2002 & 2007 & 2014 \\
\hline $\bar{N}$ & 5478 & 5150 & 5088 & 5478 & 5150 & 5088 & 11335 \\
\hline Wasted $(\mathrm{WHZ}<-2.0)$ & 37 & 34.7 & 34.5 & 50.3 & 53.7 & 44.3 & 39.9 \\
\hline Stunted $(H A Z<-2.0)$ & 7.5 & 6.8 & 8.1 & 5.4 & 5.9 & 5.9 & 6.3 \\
\hline Wasted (BMI percentile) & 7.7 & 5.6 & 5.2 & 6.1 & 5.3 & 8.3 & 5.8 \\
\hline Overweight $(\mathrm{WHZ}>2.0)$ & 9 & 7 & 6.4 & 8.1 & 7.7 & 10.7 & 7.1 \\
\hline
\end{tabular}




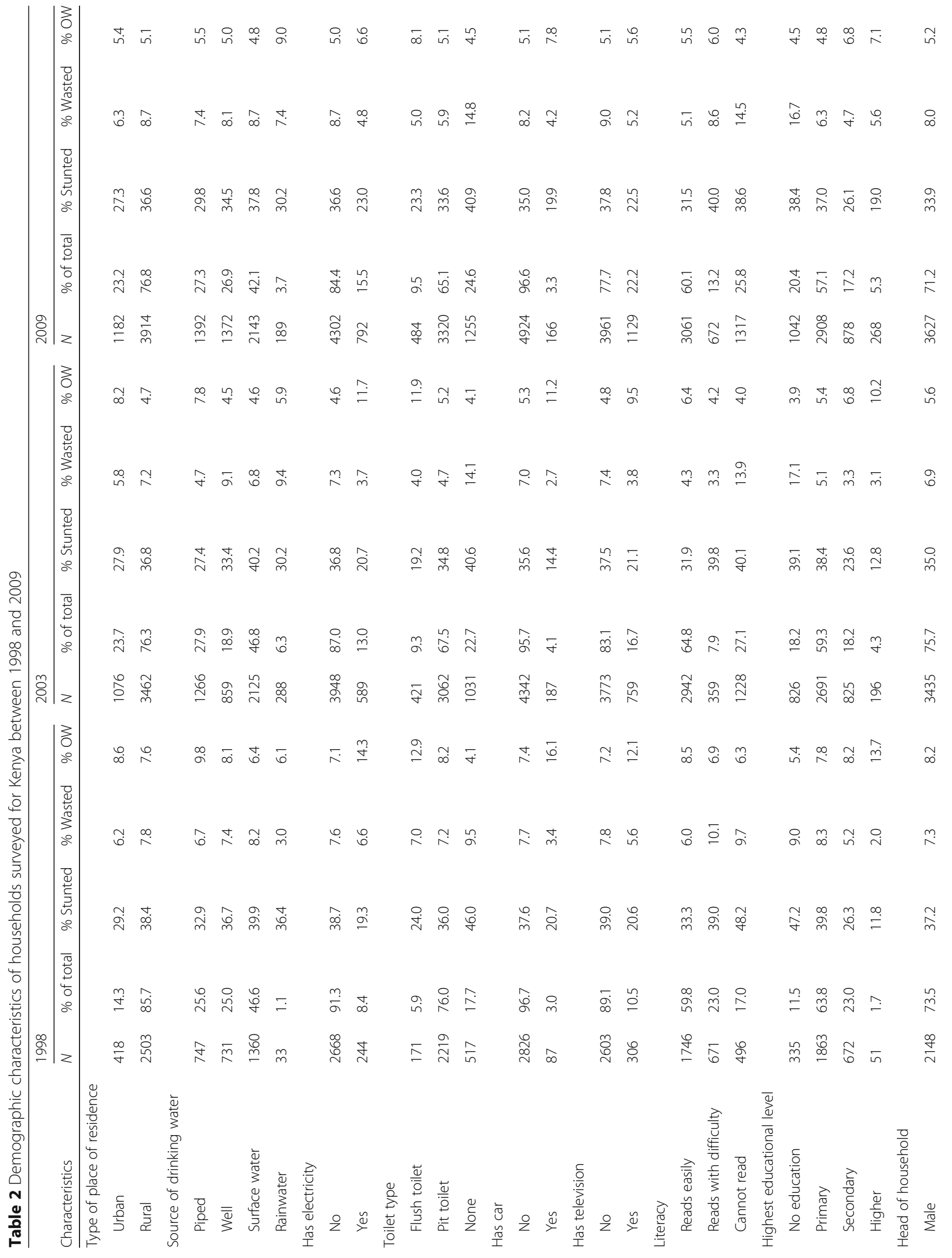


Hoffman et al. Journal of Health, Population and Nutrition (2017) 36:27

Page 5 of 13

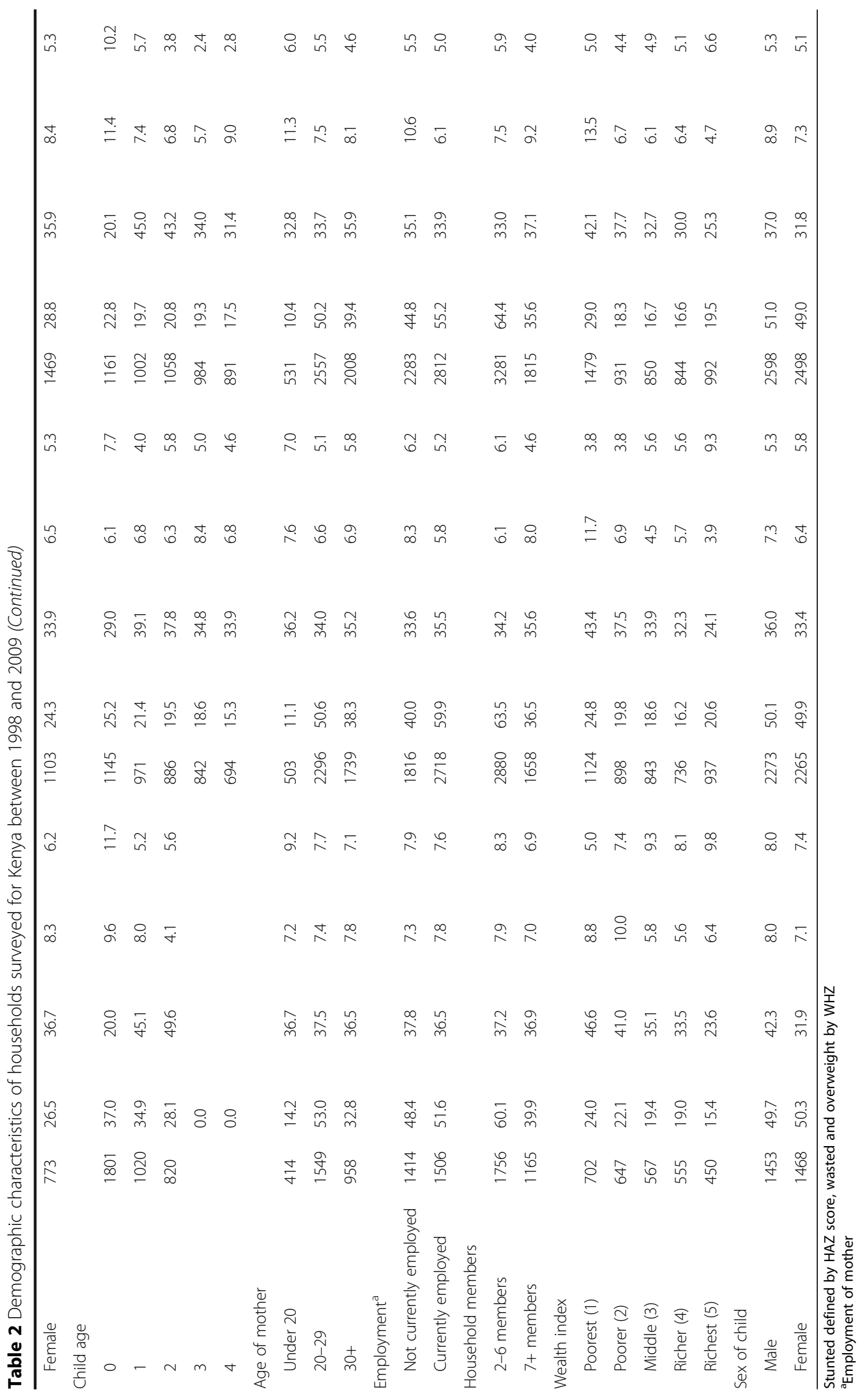


Hoffman et al. Journal of Health, Population and Nutrition (2017) 36:27

Page 6 of 13

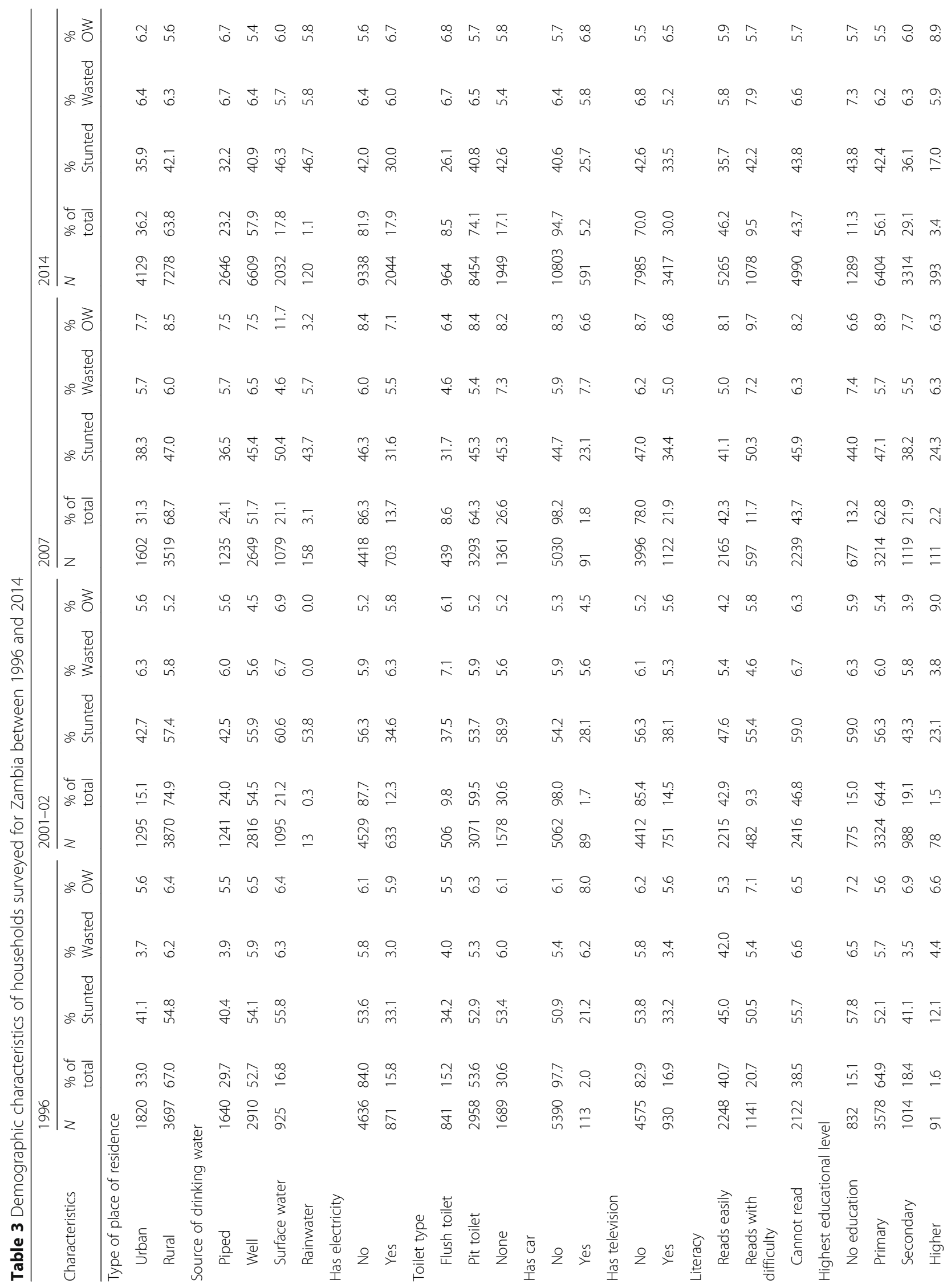




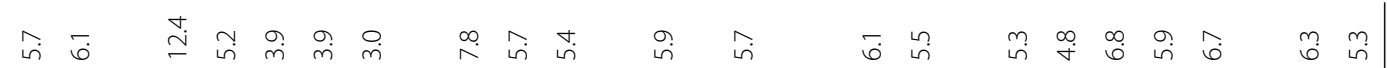

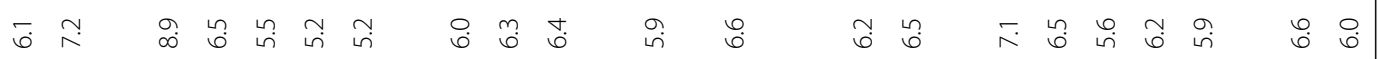

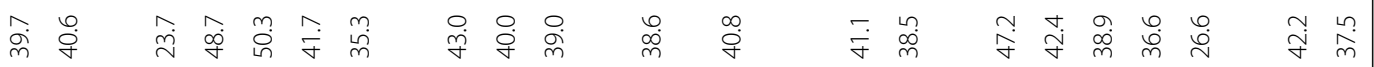

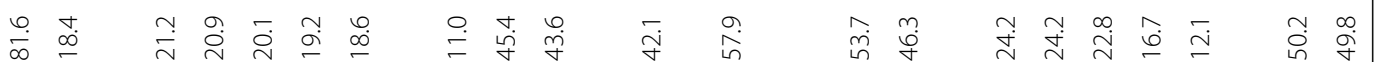

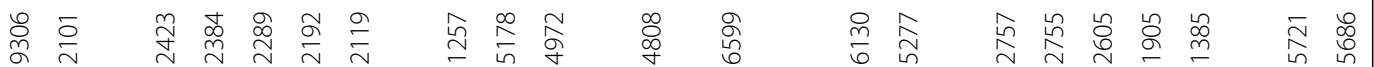

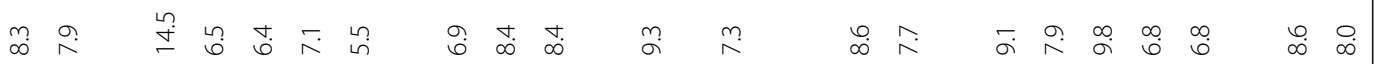

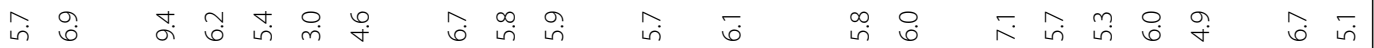

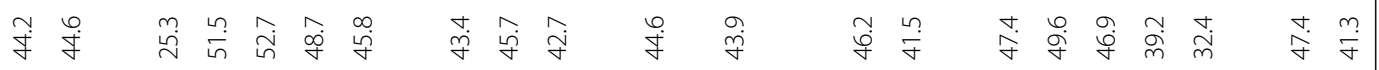

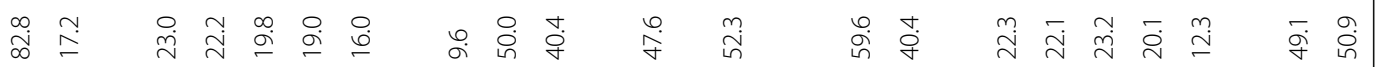

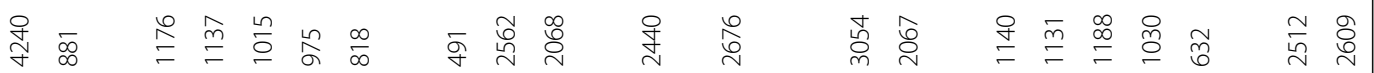

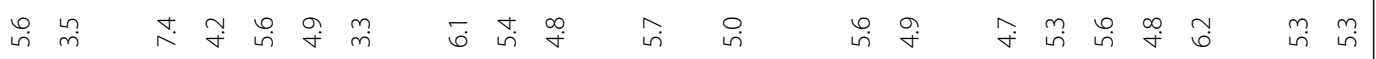

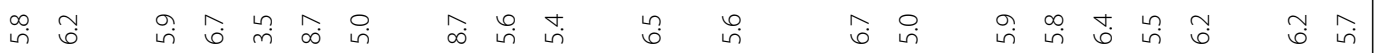

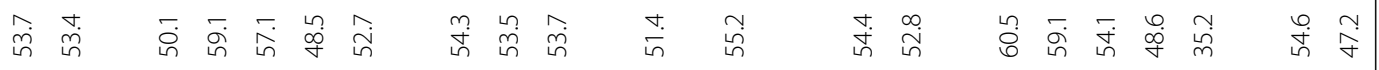

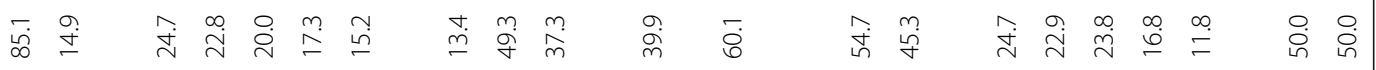

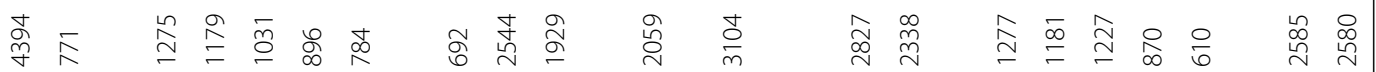
ॄ઼

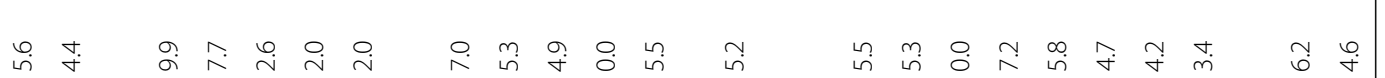

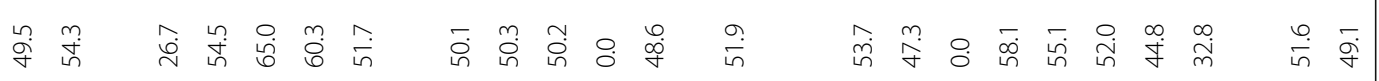

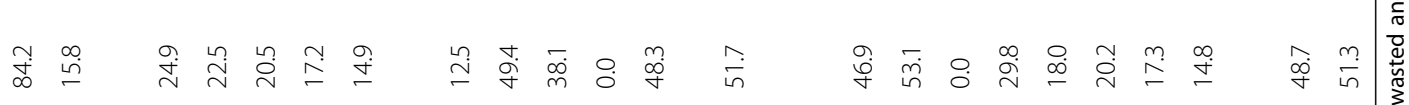

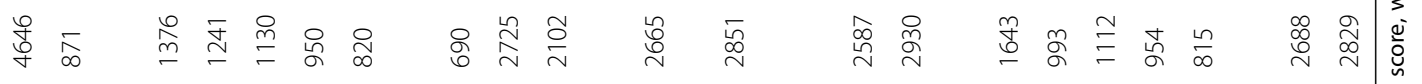




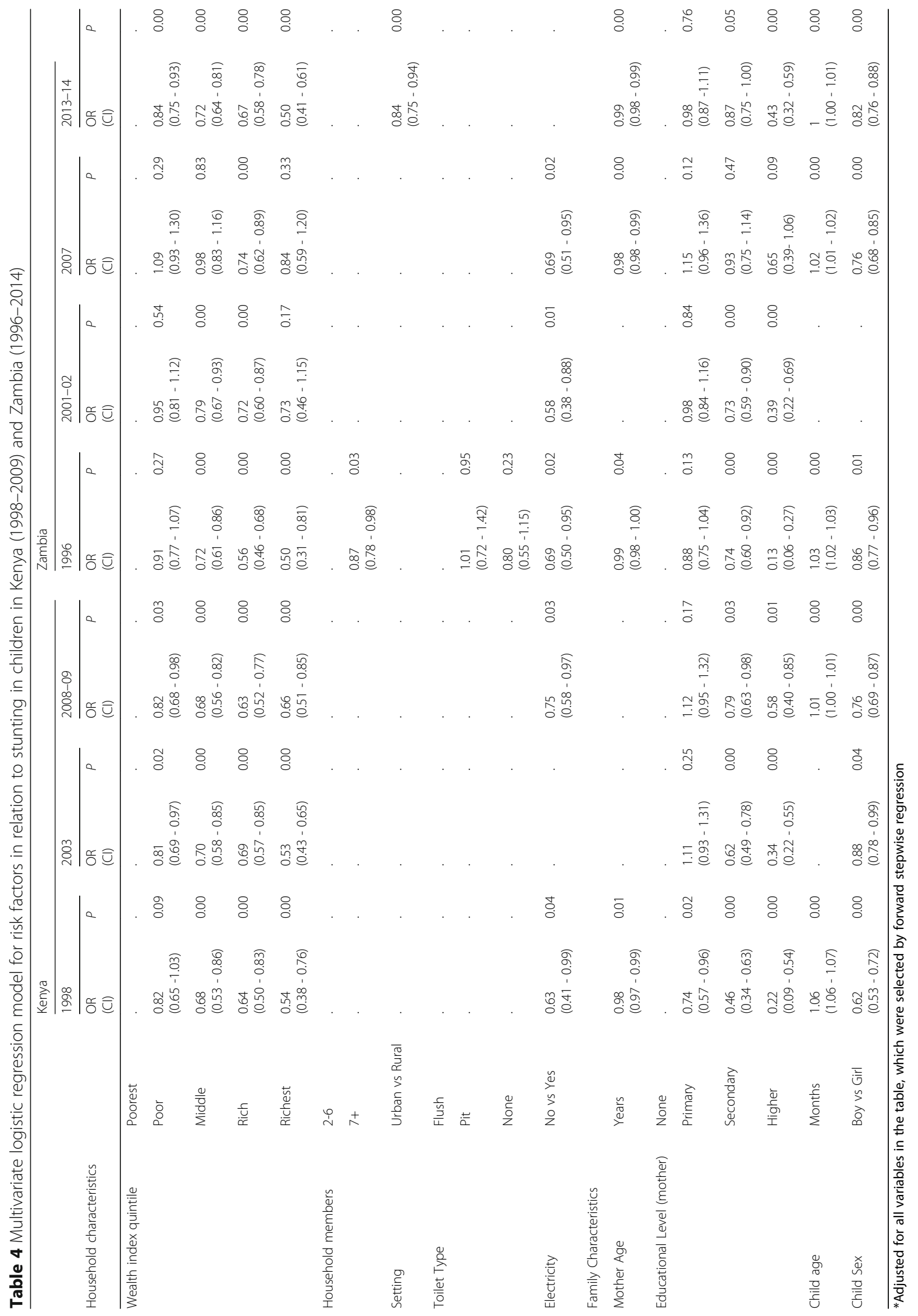




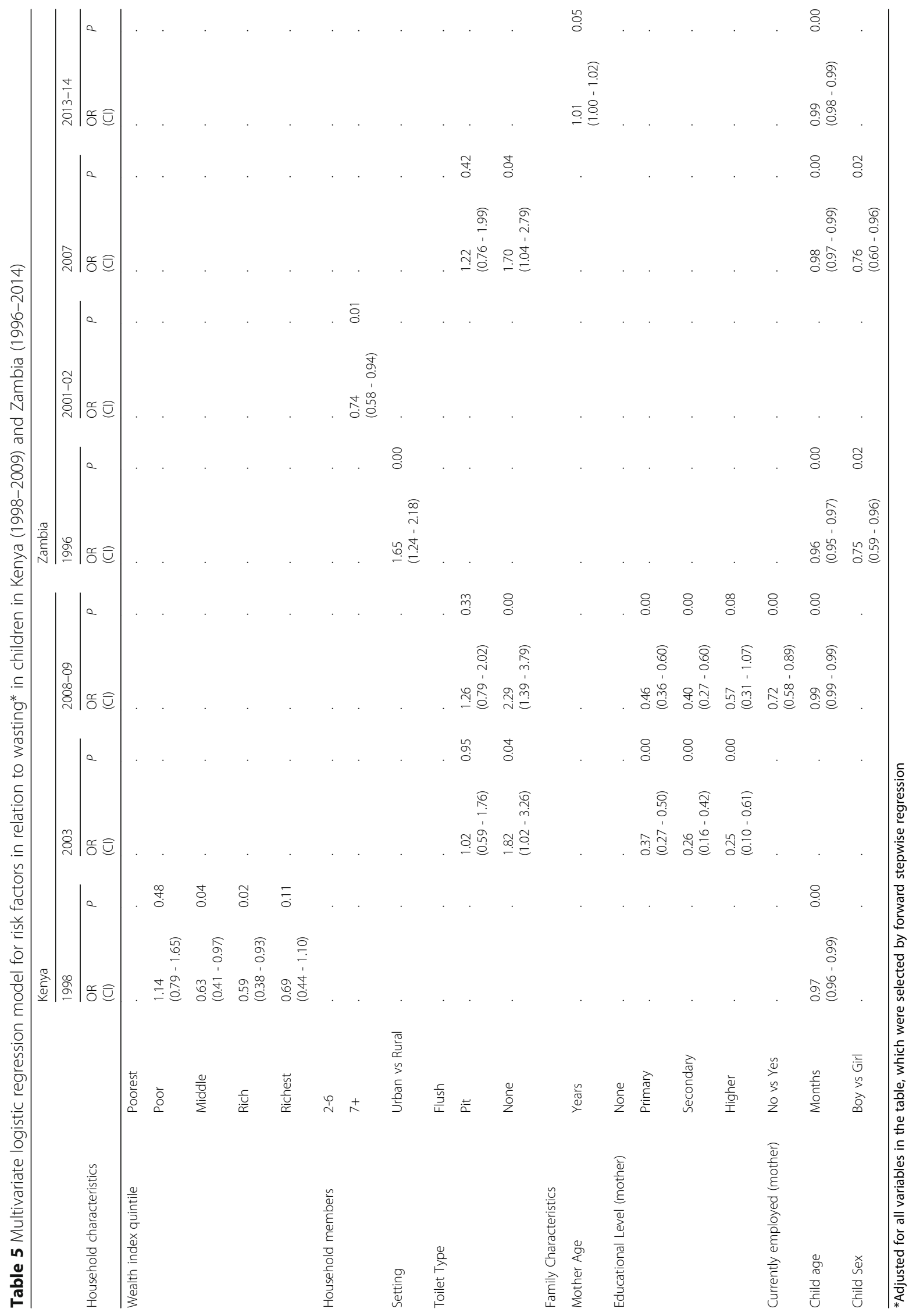


the odds of having a stunted child (1996) as did living in a rural, compared to an urban, area (2014). Also, having a flush versus pit or no toilet was protective against stunting in 1991, but not in other years. Households with electricity was protective through 2007. The results for the influence of maternal-child characteristics on stunting in Zambia were similar to Kenya such that mothers' age had a borderline protective effect and maternal education was protective, but only in 1996 and 2001.

For wasting, in Kenya, there was a protective effect of wealth on the odds of having a wasted child in 1998 only. Not having a toilet in the household, either pit or flush, increased the odds of having a wasted child by more than $80 \%$ in 2003 and over $200 \%$ in 2009. As was reported for stunting, the higher education reported by a mother decreased the odds of having a wasted child in 2003 and 2009. Finally, maternal employed decreased the odds of having a wasted child in 2009 only.

In Zambia, the relationships between socio-economic factors and wasting differed from those in Kenya. Briefly, as was reported for stunting, a large family reduced the odds of having a wasted child (2001) while living in a rural area increased the odds (1996). Not having a pit or flush toilet in 2007 increased the odds of having a wasted child, as did being a boy in 1996 and 2007 .

Summarizing the most salient outcomes, we found that the risk of stunting was higher for those with lower literacy, less education, no electricity, living in rural areas, no formal toilet, no car ownership, and those with an overall lower wealth index. This trend was consistent for both Kenya and Zambia and from year to year of available data (1998 to 2009 for Kenya and 1996 to 2014 for Zambia). Results for wasting, a condition that is a reflection of the daily nutrient intake and acute disease state, there were similar trends, but less pronounced differences between levels of each socio-economic factor.

\section{Discussion}

Undernutrition continues to be a major public health issue in Sub-Saharan Africa [23, 24], including both Kenya and Zambia [9, 25]. In fact, a number of studies have examined the nutritional status and dietary intake of children and adults in each country [11, 14]. While many of these studies have reported insufficient nutrient intake and low food security for those living in Kenya and Zambia [10,11, 14, 26], the larger context of social factors that are associated with nutritional status and how such relationships change over time need to also be recognized. Briefly, using nationally representative data over a period of ten years in Kenya and Zambia, we found that the prevalence of stunting has not changed since 1998 in Kenya, but has decreased by 20\% in Zambia since 1996. For both countries, the key predictors of chronic nutritional deficiencies (i.e., stunting) were maternal education, elements of higher socio-economic status (e.g., electricity, modern toilet, television, and piped water), while those for acute nutritional insults (i.e., wasting) included higher wealth index, type of toilet, level of maternal education, and the sex of child for some years in Zambia.

The results of our analyses are consistent with studies from other parts of Sub-Saharan Africa. In particular, as was reported by Danaei and colleagues, poor fetal growth and unsanitary conditions are the major factors predicting stunting in children under the age of 5 years [7]. This study is complemented by an economic analysis of stunting in which it was estimated stunting in SubSaharan African results in over \$18 million in lost educational attainment [27]. Thus, given the complex nature of factors that influence growth as well as the profound effects on economics, it is imperative to understand how various programs may reduce the prevalence of stunting. Nabwera et al. reported that intensive health and nutrition interventions decreased the prevalence of undernutrition by $50 \%$ in Gambia, but that more comprehensive and sustainable programs are needed to have a more significant and lasting impact on childhood health [28]. In addition, apparent differences in nutritional status between boys and girls illustrates that there may be factors that favor higher dietary intake among one gender over the other, differences in work or physical activity patterns between the two genders, or cultural preferences for one gender over the other. Simply, any of these factors could promote healthy growth or poor growth depending on the soci-economic context in which the child is exposed.

Compared to other cross-sectional studies from each country, our data clearly demonstrate that factors influencing diet and nutritional status in Kenya and Zambia have not changed appreciably in the past 20 years. For example, one study of 1000 homes in Nairobi reported that $85 \%$ of those households surveyed were food insecure and 50\% were severely food insecure [29]. The relationship between dietary, social, and environmental factors and obesity were examined in another study. A sample of 1008 women from across Kenya was used for the study, which involved anthropometric measurements and 24-h dietary recall interviews. The researchers found that overweight and obesity were highly prevalent among Kenyan women, with $43.3 \%$ of women overweight or obese. The highest prevalence of overweight and obesity occurred in women in urban areas within the highincome group [30]. The time of year was related to food security in Kenya based on the effects of the rainy and dry seasons. Using data from Meru County, it was determined that intake of energy, protein, iron, zinc, calcium, and folate increased in the rainy season and that household food security increased from the dry to the rainy season. Data was obtained from 525 households using interviews 
of mothers or caregivers [31]. A program involving educational intervention was found to increase the diversity of diets in a sample of 207 households. The intervention took place in Bondo and Teso South sub counties and consisted of training and cooking demonstrations for caregivers, which increased the children's dietary diversity scores and the caregiver's nutrition knowledge scores [32]. Surveys of adults and households illustrate the fact that many households are food insecure and reveal relationships between the nutritional status of individuals and various non-dietary factors.

Aside from those factors analyzed in this study, many other socio-demographic factors may account for the results presented, including culture, geography, maternal autonomy, and food aid [12,33]. It is clear that specific cultural groups or geographical areas within each country have varying degrees of vulnerability to food insecurity that may influence childhood nutritional status. One study of dietary intake patterns of three ethnic groups in Kenya (Luo, Kamba, and Maasai) found that the Maasai and Kamba were vulnerable to food insecurity compared to the Luo [34]. Specifically, the prevalence of underweight, a key indicator of food insecurity, was $13.7 \%$ for the Luo, 20.5\% for the Kamba, and 24.2\% for the Maasai [34]. Regarding maternal autonomy, the more independent a mother is to makes decisions related to health care, education, food, and have an independent source of income, the more likely her children are to be properly nourished [35-38]. In the Siaya, Kisumu, and Busia districts of Kenya, a high prevalence of childhood undernutrition was attributed to low maternal independence and high martial discord as childcare is not only affected by a mother's direct actions with her child, but also through her social relationships with others because of the assistance that others provide [39]. In terms of food aid, a study in the Yatta district investigated the effectiveness of using local foods to improve the nutritional status of children and found that a small food ration provided to families resulted in a lower prevalence of wasting and underweight compared to control families [40]. Similar to our results, two studies in urban settlements of Nairobi (Korogocho and Viwandani) found that a higher maternal educational status was associated with higher nutritional status of her child $[35,41]$. Therefore, based on our results and those of others, there has not been an appreciable change in the factors associated with nutritional status, suggesting potential avenues for nutrition interventions to combat undernutrition in these countries.

As with any study using nationally representative data and questionnaires, there are limitations that merit discussion. First, diet was assessed using different methodologies between waves of national data collection that could introduce bias or inconsistency between years studied. Second, it is unclear from DHS data exactly who was trained to measure nutritional status in each wave of data collection for each country. There is also limited information on quality control checks. Nonetheless, DHS data are considered reliable given that they are collected using established methods and have rigid oversight by the ministries responsible for administering the surveys. Still, the data should be treated with some degree of caution, but solid conclusions may be drawn given the established methods and near universal acceptance of these data as being nationally representative by major government and non-governmental organizations.

While the sub-Saharan countries of Kenya and Zambia have yet to begin the "nutrition transition" [42], it is clear that undernutrition is becoming less of a problem than before periods of economic growth. However, considering the analyses that demonstrate the intractable relationships between socio-economic factors and risk of poor nutritional status, future economic advances need to consider integrated approaches to improving economic standings of households without increasing the risk for overnutrition. Specifically, advancing maternal education and general household wealth without the introduction of processed foods and foods that are not part of the traditional diet are paramount. Research to improve the dietary diversity, one that includes nutrition dense and culturally acceptable foods, such as Africanindigenous vegetables, is one example of improving economic development and nutrition without the risk of excess weight gain. Rigorous studies of how such work can impact diet and health are needed and should be part of interdisciplinary approaches to improving health and nutrition in developing countries.

\section{Conclusions}

In conclusion, based on nationally representative household data, the risk for stunting in both Kenya and Zambia was higher for those with lower literacy, less education, no electricity, living in rural areas, no formal toilet, no car ownership, and those with an overall lower wealth index. Therefore, improving the education of mothers was also a significant determinant in improving the nutritional status of children in Kenya and Zambia. In addition, the need for more broad-based efforts to reduce the prevalence of undernutrition that focus on reducing the prevalence of undernutrition without promoting excess weight gain is great. As such, future economic advances need to consider integrated approaches to improving economic standings of households without increasing the risk for overnutrition.

\section{Abbreviations}

DHS: Demographic household surveys; HAZ: Height for age Z-score; WHZ: Weight for height Z-score 


\section{Acknowledgements}

We thank John Bowman, USAID-Washington and Beth Mitcham, UC-Davis for their support.

\section{Funding}

This research project is supported by the Horticulture Innovation Lab with funding from the US Agency for International Development (USAID EPA-A-00-09-00004), as part of the U.S. Government's global hunger and food security initiative called Feed the Future for the Rutgers led project "Improving Nutrition with African Indigenous Vegetables" in Eastern Africa. Funds were also provided by the New Jersey Agricultural Experiment Station, Hatch Project NJ12158.

\section{Availability of data and materials}

All datatsets are available to the public at http://microdata.worldbank.org/ index.php/home and datasets cleaned and modified for use in this paper are available upon request to the corresponding author.

\section{Authors' contributions}

DJH conceived and designed the study with input from JES. TC conducted the data collection and management. TC and PB conducted the data analyses. DJH supervised the data collection. TC wrote the first draft. All authors critically revised the draft for intellectual content. All authors read and approved the final manuscript.

\section{Competing interests}

The authors declare that they have no competing interests.

\section{Consent for publication}

Not applicable.

\section{Ethics approval and consent to participate}

Ethical approval for use of these data for this paper was provided by the Rutgers University Investigation Review Board \#E16-092.

\section{Publisher's Note}

Springer Nature remains neutral with regard to jurisdictional claims in published maps and institutional affiliations.

\section{Author details}

'Department of Nutritional Sciences, Rutgers University, New Brunswick, NJ, USA. ${ }^{2}$ New Jersey Institute for Food, Nutrition, and Health, Center for Childhood Nutrition Education and Research, Program in International Nutrition, Rutgers University, 61 Dudley Road, New Brunswick, NJ 08901, USA. ${ }^{3}$ Department of Plant Biology, Rutgers University, New Brunswick, NJ, USA.

\section{Received: 11 January 2016 Accepted: 11 May 2017}

\section{Published online: 05 June 2017}

\section{References}

1. Tzioumis E, Adair LS. Childhood dual burden of under- and overnutrition in low- and middle-income countries: a critical review. Food Nutr Bull. 2014;35:230-43.

2. Victora CG, Rivera JA. Optimal child growth and the double burden of malnutrition: research and programmatic implications. Am J Clin Nutr. 2014; 100:1611S-2.

3. Wojcicki JM. The double burden household in sub-Saharan Africa: maternal overweight and obesity and childhood undernutrition from the year 2000: results from World Health Organization Data $(\mathrm{WHO})$ and Demographic Health Surveys (DHS). BMC Public Health. 2014;14:1124.

4. Zeba AN, Delisle HF, Renier G, Savadogo B, Baya B. The double burden of malnutrition and cardiometabolic risk widens the gender and socioeconomic health gap: a study among adults in Burkina Faso (West Africa). Public Health Nutr. 2012;15:2210-9.

5. Zhang N, Becares L, Chandola T. Patterns and determinants of doubleburden of malnutrition among rural children: evidence from China. PLoS ONE. 2016:11:e0158119.

6. Subramanian SV, Kawachi I, Smith GD. Income inequality and the double burden of under- and overnutrition in India. J Epidemiol Community Health. 2007:61:802-9.
7. Danaei G, Andrews KG, Sudfeld CR, et al. Risk factors for childhood stunting in 137 developing countries: a comparative risk assessment analysis at global, regional, and country levels. PLoS Med. 2016;13:e1002164.

8. Ayaya SO, Esamai FO, Rotich J, Olwambula AR. Socio-economic factors predisposing under five-year-old children to severe protein energy malnutrition at the Moi Teaching and Referral Hospital, Eldoret, Kenya. East Afr Med J. 2004;81:415-21.

9. Hautvast JL, van der Heijden LJ, Luneta AK, van Staveren WA, Tolboom JJ, van Gastel SM. Food consumption of young stunted and non-stunted children in rural Zambia. Eur J Clin Nutr. 1999:53:50-9.

10. Kwena AM, Terlouw DJ, de Vlas SJ, et al. Prevalence and severity of malnutrition in pre-school children in a rural area of western Kenya. Am J Trop Med Hyg. 2003:68:94-9.

11. Olack $B$, Burke $H$, Cosmas $L$, et al. Nutritional status of under-five children living in an informal urban settlement in Nairobi, Kenya. J Health Popul Nutr. 2011;29:357-63.

12. Termote C, Raneri J, Deptford A, Cogill B. Assessing the potential of wild foods to reduce the cost of a nutritionally adequate diet: an example from eastern Baringo District, Kenya. Food Nutr Bull. 2014:35:458-79.

13. Trykker H, Simwambana A, Kantu K, Eberhard M. A primary health care baseline survey in a rural district in Zambia. Afr J Med Med Sci. 1994;23:147-51.

14. Mwaniki EW, Makokha AN. Nutrition status and associated factors among children in public primary schools in Dagoretti, Nairobi, Kenya. Afr Health Sci. 2013:13:39-46.

15. Semproli S, Canducci E, Ricci E, Gualdi-Russo E. Nutrient intake in 5-17-year-old African boys and girls in a rural district of Kenya. Nutr Hosp. 2011;26:765-74.

16. Ndiku M, Jaceldo-Siegl K, Singh P, Sabate J. Gender inequality in food intake and nutritional status of children under 5 years old in rural Eastern Kenya. Eur J Clin Nutr. 2011;65:26-31.

17. Cole SM. The relationship between relative deprivation and adult nutritional status in rural Zambia. Am J Hum Biol. 2012;24:800-5.

18. Kenya Country Report. World Bank Group, Washington, DC, USA. World Bank; 2016.

19. Zambia Country Report. World Bank Group, Washington: World Bank; 2016.

20. Living Standards Measurement Study. World Bank Group, Washington: World Bank; 2015.

21. Demographic and health survey sampling and household listing manual. Calverton, MD, USA. ICF International; 2012

22. WHO. In: de Onis M, editor. Database on child growth and malnutrition Geneva: World Health Organization; 1997. p. 67.

23. Black RE, Allen LH, Bhutta ZA, et al. Maternal and child undernutrition: global and regional exposures and health consequences. Lancet. 2008;371:243-60.

24. Amugsi DA, Dimbuene ZT, Kimani-Murage EW, Mberu B, Ezeh AC. Differential effects of dietary diversity and maternal characteristics on linear growth of children aged 6-59 months in sub-Saharan Africa: a multi-country analysis. Public Health Nutr. 2017:09:1-17.

25. Kigutha HN, van Staveren WA, Veerman W, Hautvast JG. Child malnutrition in poor smallholder households in rural Kenya: an in-depth situation analysis. Eur J Clin Nutr. 1995;49:691-702.

26. Semproli S, Gualdi-Russo E. Childhood malnutrition and growth in a rural area of Western Kenya. Am J Phys Anthropol. 2007;132:463-9.

27. Fink $G$, Peet $E$, Danaei $G$, et al. Schooling and wage income losses due to early-childhood growth faltering in developing countries: national, regional, and global estimates. Am J Clin Nutr. 2016:104:104-12.

28. Nabwera HM, Fulford AJ, Moore SE, Prentice AM. Growth faltering in rural Gambian children after four decades of interventions: a retrospective cohort study. Lancet Glob Health. 2017;5:e208-16.

29. Kimani-Murage EW, Schofield L, Wekesah F, et al. Vulnerability to food insecurity in urban slums: experiences from Nairobi, Kenya. J Urban Health. 2014;91:1098-113.

30. Steyn NP, Nel JH, Parker WA, Ayah R, Mbithe D. Dietary, social, and environmental determinants of obesity in Kenyan women. Scand J Public Health. 2011:39:88-97.

31. M'Kaibi FK, Steyn NP, Ochola S, Du Plessis L. Effects of agricultural biodiversity and seasonal rain on dietary adequacy and household food security in rural areas of Kenya. BMC Public Health. 2015;15:422.

32. Waswa LM, Jordan I, Herrmann J, Krawinkel MB, Keding GB. Communitybased educational intervention improved the diversity of complementary diets in western Kenya: results from a randomized controlled trial. Public Health Nutr. 2015;18:3406-19. 
33. Gewa CA, Murphy SP, Weiss RE, Neumann CG. Determining minimum food intake amounts for diet diversity scores to maximize associations with nutrient adequacy: an analysis of schoolchildren's diets in rural Kenya. Public Health Nutr. 2014;17:2667-73.

34. Hansen AW, Christensen DL, Larsson MW, et al. Dietary patterns, food and macronutrient intakes among adults in three ethnic groups in rural Kenya. Public Health Nutr. 2011;14:1671-9.

35. Abuya BA, Ciera J, Kimani-Murage E. Effect of mother's education on child's nutritional status in the slums of Nairobi. BMC Pediatr. 2012;12:80.

36. Carlson GJ, Kordas K, Murray-Kolb LE. Associations between women's autonomy and child nutritional status: a review of the literature. Matern Child Nutr. 2015;11:452-82

37. Brunson EK, Shell-Duncan B, Steele M. Women's autonomy and its relationship to children's nutrition among the Rendille of northern Kenya. Am J Hum Biol. 2009:21:55-64.

38. Ziaei S, Contreras M, Zelaya Blandon E, Persson LA, Hjern A, Ekstrom EC. Women's autonomy and social support and their associations with infant and young child feeding and nutritional status: community-based survey in rural Nicaragua. Public Health Nutr. 2015;18:1979-90

39. Whyte SR, Kariuki PW. Malnutrition and gender relations in Western Kenya. Health Transit Rev. 1991;1:171-87.

40. Tomedi A, Rohan-Minjares F, McCalmont K, Ashton R, Opiyo R, Mwanthi M. Feasibility and effectiveness of supplementation with locally available foods in prevention of child malnutrition in Kenya. Public Health Nutr. 2012;15:749-56.

41. Mukudi E. Nutrition status, education participation, and school achievement among Kenyan middle-school children. Nutrition. 2003;19:612-6.

42. Popkin BM. Nutrition transition and the global diabetes epidemic. Curr Diab Rep. 2015;15:64.

\section{Submit your next manuscript to BioMed Central and we will help you at every step:}

- We accept pre-submission inquiries

- Our selector tool helps you to find the most relevant journal

- We provide round the clock customer support

- Convenient online submission

- Thorough peer review

- Inclusion in PubMed and all major indexing services

- Maximum visibility for your research

Submit your manuscript at www.biomedcentral.com/submit

) Biomed Central 